\title{
Preparation and Characterization of MMA/MAA/BA/VeoVa-10 Quaternary Co-polymer emulsion
}

\author{
Mingguang $\mathrm{Hu}{ }^{\mathrm{a}}$, Han $\mathrm{Cui}^{\mathrm{b}}$, Zhen $\mathrm{Yu}^{\mathrm{c}}$, Liangchen Xing ${ }^{\mathrm{d}}$ and Jijun Xiao ${ }^{\mathrm{e}, *}$ \\ School of Hebei University of Science and Technology, Hebei 050000, China; \\ a1297133041@qq.com, bcuihan18032831773@126.com, \\ c1316080815@qq.com,d961687775@qq.com, ${ }^{\mathrm{e}} \mathrm{j} j \mathrm{jjunxiao@aliyun.com}$
}

Keywords: Quaternary Co-polymer Emulsion, VeoVa-10, properties, Characterization.

\begin{abstract}
In order to get good weather resistance, water repellency, and thermal stability of emulsion lattices, the present work aimed to prepare Quaternary Co-polymer Emulsion, therefore, a conventional seeded emulsion polymerization is prepared by $\left(\mathrm{NH}_{4}\right)_{2} \mathrm{~S}_{2} \mathrm{O}_{8}$-initiation and by core/shell technique of four monomers namely MMA, BA, MAA, and VeoVa-10. As a result, stable Tertiary acrylic emulsion with improved physico-mechanical properties were obtained. The effect of the VeoVa-10 and emulsifier content on the properties of the resulting emulsion lattices and their corresponding films were investigated and achieved enhanced and excellent properties. Characterization of the prepared emulsions was performed using e.g. IR, TEM, SEM, thermal analysis. The VeoVa-10 and emulsifier amount had a great influence on the properties of the resulting lattices and their corresponding films.
\end{abstract}

\section{Introduction}

Aqueous acrylic polymer emulsions are friendly to the environment and as time goes by they tend to replace solvent based binders in several coatings and adhesive applications to protect our health and to ensure safety. Furthermore, the replacement of solvent based binders with water based binders is imposed by recent legislation which has been developed mainly in Europe and North America with respect to the replacement or reduction of organic solvents (VOCs) in the last decade. The vinyl ester of Versatic acid 10, known as Veova 10, is one such product which is a very attractive monomer for polymer manufacture through reactions of the vinyl group [1]. The solubility of Veova-10 in water is very low $<0.001 \%$ compared to that of butyl acrylate which is $0.16 \%$ and that of methyl methacrylate which is $1.5 \%$ [2]. With a chemical formula of $\mathrm{C}_{12} \mathrm{H}_{22} \mathrm{O}_{2}$, it possesses a combination of flexibility, hydrophobicity and very good chemical and UV resistance [3].Microemulsion co-polymerization of methyl methacrylate(MMA) with butyl acrylate (BA) in the presence of Aerosol A-102, used as surfactant, and methyl acrylate or acrylate and 2-hydroxyethyl methacrylate (HEMA) used as reactive cosurfactants, gave polymer nanoparticles with average diameters $\leq 60 \mathrm{~nm}$, and polymer content about $30 \mathrm{wt} \%$ [4]. The main objective of our work was to use efficient combinations of surfactants to produce stable translucent Nano-lattices of MMA/BA/Veova-10 Terpolymer which can be applied in waterborne coatings without using organic solvents.

\section{Experiment}

\subsection{Material}

Butyl acrylate $99.5 \%$ (BA), methacrylic acid glacial 99.5\% (MAA) are supplied from BASF (Ludwigshafen, Germany). Methyl methacrylate 99.9\% (MMA) is supplied from Degussa Röhm GmbH (Darmstadt, Germany). VeoVa-10 is supplied from TJSHIELD (Tianjin four Friends of Fine Chemicals Limited).

\subsection{Synthesis of Quaternary Co-polymer Emulsion}

A certain amount of compound emulsifier were measured and dissolved with the appropriate distilled water. Then, $5 \%$ distilled water,and complex emulsifier solution were added to a $500 \mathrm{ml}$ four-necked 
flask equipped with a stirrer. Finally, feeding $85 \%$ monomer MMA, MAA, BA and VeoVa-10 slowly to the four-necked flask and emulsify for at least 30 minutes to prepare the monomer pre-emulsion.

A mixture of $15 \%$ distilled water, formulated complex emulsifier, monomers of MMA, MAA, BA and VV-10 were fed to a four-necked flask equipped with a stirrer. And then adding about $25 \%$ of the prepared initiator and buffer solution, the temperature of the water bath was set from $80^{\circ} \mathrm{C}$ to $82.5{ }^{\circ} \mathrm{C}$. When appearing the blue light in the bottle, it was the time to start insulation at least 30 minutes.

After insulation, dropping the pre-emulsion and the remaining monomer initiator and buffer solution into the four-necked flask equipped with a stirrer at the same time. You had better control the rate of drop so that it drops within 3.5 hours finished ( It should not drop less than 3 hours at least, paying attention to observe the blue light change in the process of dropping.). Afterwards, stopping the water bath heating when the reaction was completed within 1.5 hours. While the four-necked flask cooling down to $40{ }^{\circ} \mathrm{C}$ below, it was time to adjust the $\mathrm{pH}$ value of the emulsion with ammonia from 7 to 8 . Finally, with 240 mesh filter cloth filtering out the emulsion.If the emulsion contained foam, feeding 1-2 drops of defoamer.

\subsection{Characterization}

Fourier transform infrared (FTIR) spectra of the products were collected on a Nicolet iS5 Fourier transform infrared (FT-IR) instrument (Thermo Fisher Scientific,Madison,USA).

TGA instrument were performed on METTLER TOLEDO. 5 10mg of sample were heated from $30^{\circ} \mathrm{C}$ to $600^{\circ} \mathrm{C}$ with a heating rate of $10^{\circ} \mathrm{C} / \mathrm{min}$ under a nitrogen atmosphere.

The water absorption was an important parameter for characterizing the hydrophobicity of the latex film. The prepared emulsion was coated on a transparent PP sheet for 24 hours, and then weighing $0.15 \mathrm{~g}-0.3 \mathrm{~g}$ the small piece of coating to immerse in the same amount of ionic water 12 hours, observing the coating until no longer change.Finally, Calculating the water absorption according to the following formula (1):

Water Absortion $=($ M2-M1) $/ \mathrm{M} 1 * 100 \%$

$\mathrm{M}_{1}$ - the quality of the sample before water absorption;

$\mathrm{M}_{2}$ - the quality of the sample after water absorption.

\section{Result and Discussion}

\subsection{Infrared Analysis of Quaternary Co-polymer Emulsion}

Fig. 1 showed the FT-IR spectra of Quaternary co-polymer emulsion.

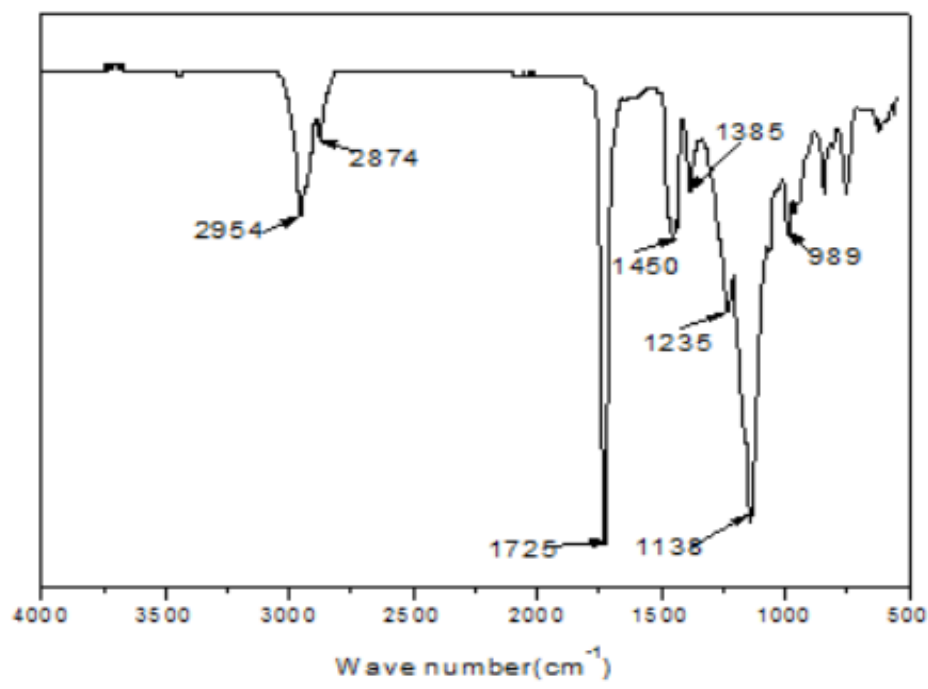

Figure 1. FT-IR curves of Quaternary co-polymer emulsion

As shown in Fig. 1, the absorption band at $1725 \mathrm{~cm}^{-1}$ represented the carbonyl $(\mathrm{C}=\mathrm{O})$ stretching vibration, and the absorption band at 2874 and $2954 \mathrm{~cm}^{-1}$ were attributable to the $\mathrm{CH}_{3}$ stretching vibration of MMA and MAA components. Furthermore, the characteristic absorption peaks near 1235 and $1138 \mathrm{~cm}^{-1}$ were caused by the symmetrical contraction vibration of $-\mathrm{C}-\mathrm{O}-$, the bands occurring at 
1450 and $1385 \mathrm{~cm}^{-1}$ assigned to the $\mathrm{CH}_{2}$ and $\mathrm{CH}_{3}$ bending vibration, the band at $989 \mathrm{~cm}^{-1}$ represented $-\mathrm{CH}=\mathrm{CH}_{2}$ of BA component. Finally, It was vital to observe that there is no the acrylic $\mathrm{C}=\mathrm{C}$ stretching vibration characteristics of the peak near $1650 \mathrm{~cm}^{-1}$, It could be concluded that several monomers in the tertiary emulsion are all involved in the co-polymerization reaction.

\subsection{TGA of Quaternary Co-polymer Emulsion}

Fig.2 showed the TGA curves of Quaternary co-polymer emulsion film.

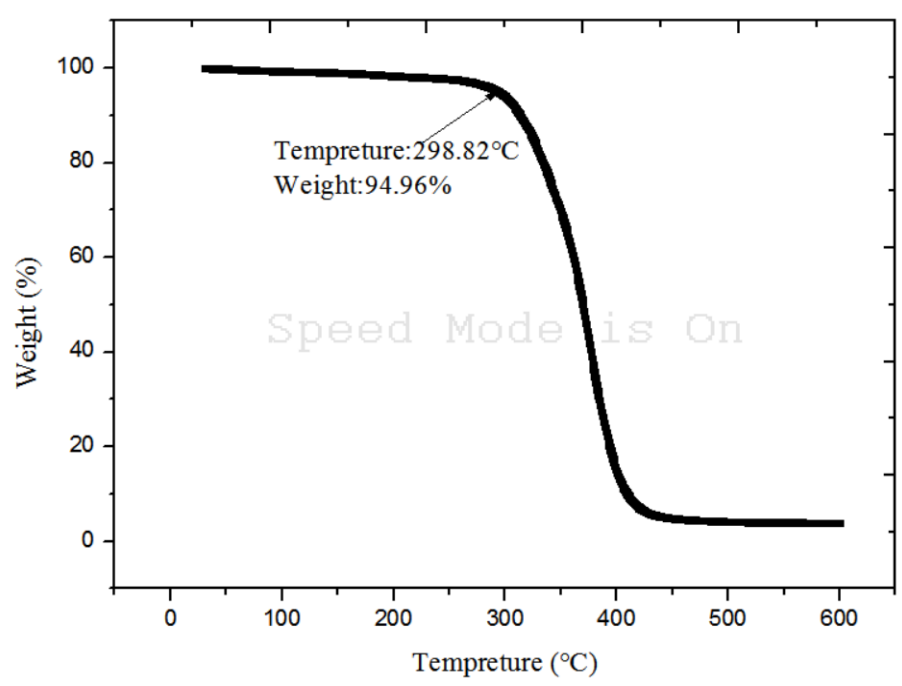

Figure 2. TGA curves of Quaternary co-polymer emulsion film

From Fig.2, it was seen that the film is decomposed at around $300^{\circ} \mathrm{C}$, proving that the Quaternary co-polymer emulsion film possesses excellent heat resistance.

\subsection{Water Absorption of Quaternary Co-polymer Emulsion Film}

Fig.3 showed the water absorption curves of Quaternary co-polymer emulsion film.

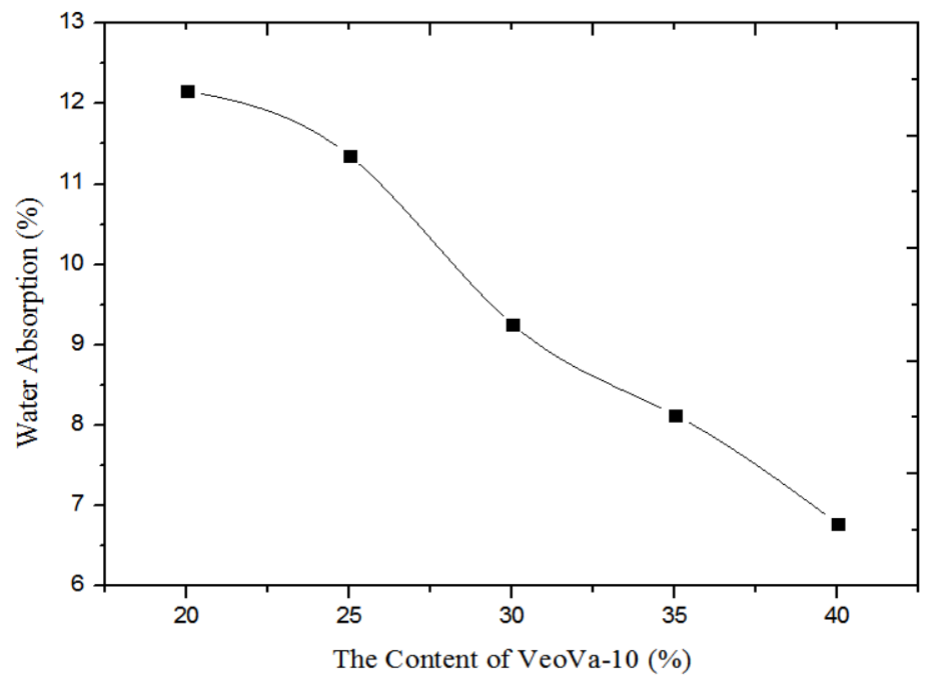

Figure 3. The Water Absorption curves of Quaternary co-polymer emulsion film

Fig.3 exhibited that the water absorption of the film was reduced with the content of VeoVa-10 addition. If we wanted to improve the water resistance, it is a good choice to add the appropriate amount of VeoVa-10.

\section{Result and Discussion}

A new approach for enhancing the heat resistance and water resistance had been introduced, by which well-compatibilized MAA, MAA, BA, and VeoVa-10 composites were obtained, which show considerably improved thermal performance. In addition, the water repellency was improved with the amount of VeoVa-10 increasing. More detailed studies relating to the Quaternary co-polymer emulsion are being undertaken in our laboratory. 


\section{References}

[1]. Shell Chemicals Material Safety Data Sheet Veova 10, http://www.sfm.state.or.us

[2]. CR2K.SubDB/MSDS/VEOVA 10.PD

[3]. D.R. Bassett,Hydophobic coatings from emulsion polymers, J. Coat. Technol. (January, 2001).

[4]. Momentive Technical Data Sheet Veova 10,http://www.momentive.com

[5]. /products/Technical/Data/Sheet.aspx ?id=5994

[6]. Y. Zhang, T. Guo, G. Hao, M. Song, B. Zhang, J. Appl. Polym. Sci. 90 (2003) 3625-3630. 